\title{
Evolution analysis of industrialization process in Inner Mongolia
}

\author{
Jianghong Zhen \\ College of Geography Science, Inner Mongolia Normal University \\ Huhhot, China \\ zhenjianghong@sina.com
}

\begin{abstract}
Correctly judge the development phases of regional industrialization and its evolution characteristics has an important significance to promote the development of regional economy and to speed up the process of industrialization. Based on the connotation and characteristics of industrialization, this paper constructs the industrialization comprehensive evaluation index system, standard and model. Analytical Hierarchy Process, Principal Component Analysis and Weighted Synthesis Method are used in the paper to measure and analyze the industrialization process and the evolution characteristics of Inner Mongolia during the period of 1990 to 2010. The results show that: The industrialization process has continuously improved in Inner Mongolia since 1990 and it has entered the middle stage of industrialization; the industrial development speed has stage characteristics in Inner Mongolia during the study period. It has entered the stage of accelerated industrialization since 2000. The development level and development trend of each component index were not balanced. The industrialization level index is higher and the informatization level index is lower; the development speed of the information is rapidly and the science and technology is slowly.
\end{abstract}

Key words: Inner Mongolia, industrialization, comprehensive index, evolution characteristics, assessment

\section{I .INTRODUCTION}

Industrialization is the theme of economic development and an important stage of social development. As an important issue in development economics, research on industrialization has begun since 1930s. The division of industrialization stage and the measure of industrialization process is the hot research topic in recent years. At present, the domestic academic research about the measure on industrialization process mainly focus on three aspects ${ }^{[1]}$ : First, it is the measure and analysis of industrialization process based on personal formulate industrial standards; Second, it is the judgment and assessment on industrialization process of China or some regions base on the western economists theory and the general industrialization index; Third, it is the calculation of industrialization comprehensive index base on the evaluation index and quantitative method. Because of the comprehensive index method is able to reflect the comprehensive characteristics of regional industrialization, it has been widely used and recognized. Many scholars have assessed and analyzed the industrialization level of China and some provinces through constructing the comprehensive evaluation index system ${ }^{[1-5]}$. Some scholars analyzed the level of industrialization in Inner Mongolia from different angles and different standards, but the dynamic evolution analysis on its industrialization process is seldom reported.
Inner Mongolia is located in the north of China, it is an important national energy, raw materials and chemical industry base. In recent years, with the advantageous of resources and location, Inner Mongolia has formed the industrial system which including six major industries such as energy, metallurgy, chemical industry, equipment manufacturing, agricultural and livestock products processing and high-tech industry. Since 2003, the growth rate of the added value of industrial enterprises above designated size has maintained the first in the country for 6 consecutive years, and the contribution rate of the second industry to economic growth is more than $60 \%$. The industry has become the leading force in economic development. It has an important guiding significance and practical value to accelerate the process of industrialization to judge the industrialization evolution stage of Inner Mongolia correctly. In order to provide reference for the further research on the regional economic development, this paper uses the comprehensive index method to determine and analyze the industrialization development stages and evolution characteristics of Inner Mongolia.

\section{II .EVALUATION INDEX SYSTEM AND STANDARD}

\section{OF INDUSTRIALZATION IN INNER MONGOLIA}

Industrialization is the process of the share of industry in the national income and labor population continuous rising, but it is also the process of economic development and social change $^{[6]}$. Continuous growth in per capita income, upgrading in industrial structure, gradually optimization of production mode, a substantial increase in production efficiency and the continuous change of social structure, employment structure, demand structure, supply structure and the urban and rural population distribution structure, which are the main indicator of industrialization ${ }^{[7]}$. At present, there is no unified standard and index system for measuring the industrialization process. Base on the related research and the connotation and characteristics of industrialization and the industrialization practice in Inner Mongolia, this paper constructs the comprehensive evaluation index system of industrialization (Table I ).The principle such as representative, comprehensive, feasibility and comparability were followed in the process of index selection. Industrial development stages and the standard value of different stages (Table I ) are determined according to the industrialization stage theory which are widely used in the world, domestic and foreign academic research achievements, the strategic goal of realizing industrialization and national economic and social development and long-term planning of China. 

MONGOLIA

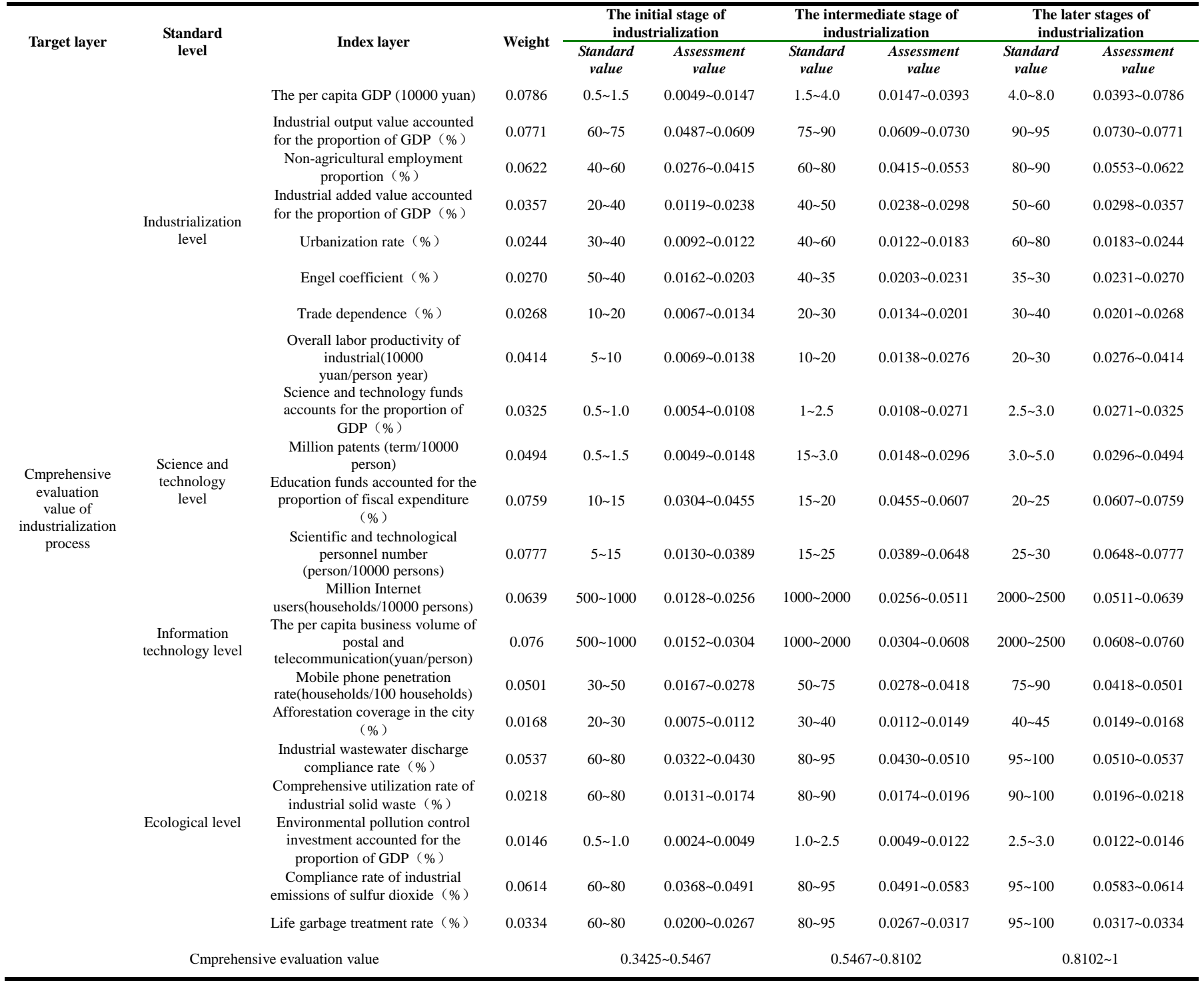

\section{COMPREHENSIVE EVALUATION OF THE INDUSTRIALZATION PROCESS IN INNER MONGOLIA}

\section{A. Data sources and processing}

The original data of the index mainly originates from the 《Inner Mongolia Statistical Yearbook》 (1990 2010), 《China City Statistical Yearbook》(1990 2010). In order to make the data comparable and to eliminate the units and dimension, the following formula were used in the process of data standardization.

$$
\begin{aligned}
& Y_{i}=X_{i} / X_{i 0} \\
& Y_{i}=X_{i 0} / X_{i}
\end{aligned}
$$

In the equation, $\mathrm{Y}_{\mathrm{i}}$ is the index of standardized value, $\mathrm{X}_{\mathrm{i}}$ is the actual value of index, $X_{i 0}$ is the standard values of index. Among them, the positive index using the equation (1); the inverse index using the equation (2). When the index value is greater than the standard value, using standard numerical value as the index finger.

\section{B. The weight of evaluation index}

Comprehensive weighting method which combining subjective and objective view was used in this paper to determine the weight of each evaluation index (Table I ). The calculation process is: First, according to the importance of experts on the index, using Analytical Hierarchy Process to determine the subjective weight of each index; Second, using Principal Component Analysis method to determine the objective weight of each index; Third, using the multiplicative synthesis normalization method to calculate the comprehensive weight, the calculation formula is:

$$
W_{\mathrm{i}}=p_{i}+q_{i} / \sum_{i=1}^{n}\left(p_{i}+q_{i}\right)
$$

In the equation, $\mathrm{i}=1,2, \ldots \mathrm{n} ; \mathrm{W}_{\mathrm{i}}$ is the integrated weight; $\mathrm{p}_{\mathrm{i}}$ is the subjective weight, $\mathrm{q}_{\mathrm{i}}$ is the objective weight.

C. Calculation of the comprehensive evaluation value and phase definition 
Weighted Synthesis method was used in this paper to calculate the comprehensive evaluation value of industrialization of Inner Mongolia. The calculation formula is:

$$
I=\sum_{i=1}^{n} W_{i} Y_{i}
$$

According to the equation (4), the comprehensive scores of each stage of industrialization (Table I ) and the comprehensive evaluation value of industrialization process in Inner Mongolia during 1990 to 2010 years can be calculated (Figure 1). From table I, the comprehensive evaluation value is between $0.3425 \sim 0.5467$ for the initial stages of industrialization development, comprehensive evaluation value is between 0.5467 0.8102 for the intermediate stage of industrialization, the comprehensive evaluation value is greater than 0.8102 will enter into the later stages of industrialization.

\section{EVOLUTION ANALYSIS OF THE INDUSTRIALZATION PROCESS IN INNER MONGOLIA}

\section{A. The level of industrialization has continuously improved in Inner Mongolia}

Figure 1 shows that the comprehensive evaluation value of industrialization process in Inner Mongolia have a larger growth during 1990 to 2010, it increased to 0.6499 from 0.2381 , increased 1.73 times. It showed that the level of industrialization has continuously improved in 21 years.

\section{B. The industrialization process in Inner Mongolia has entered the intermediate stage of industrialization.}

According to the comprehensive score standard of each industrialization stage (Table I ), the industrialization comprehensive evaluation value in Inner Mongolia reached 0.3550 in 2002 , it showed that the industrialization process entered the initial stage; the industrialization comprehensive evaluation value in Inner Mongolia reached 0.5484 in 2007, it showed that the industrialization process entered the intermediate level. It is visible that Inner Mongolia has entered the middle stage of industrialization at present.

C. The development speed of industrialization in Inner Mongolia has stage characteristics, it has entered the accelerated development stage

The development speed of industrialization in Inner Mongolia is not balanced during the study period. It revealed the stages increasing characteristic. During 1990 to 1999, the industrialization comprehensive evaluation value in Inner Mongolia fluctuated slightly but the growth speed was slow, the industrialization comprehensive evaluation value increased to 0.2808 from 0.2381 , with an increase of 0.18 times and an average annual growth rate of $1.66 \%$. During 2000 to 2010, the industrialization comprehensive evaluation value in Inner Mongolia showed a linear growth trend, it increased to 0.6499 from 0.3268 , with an increase of 0.99 times and an average annual growth rate of $6.45 \%$. Visible, the development speed of industrialization in Inner Mongolia has the stages increasing characteristic. Since 2000, with the implement of the western development strategy and transformation of the industrial growth mode, industrialization development speed is rapid, it has entered

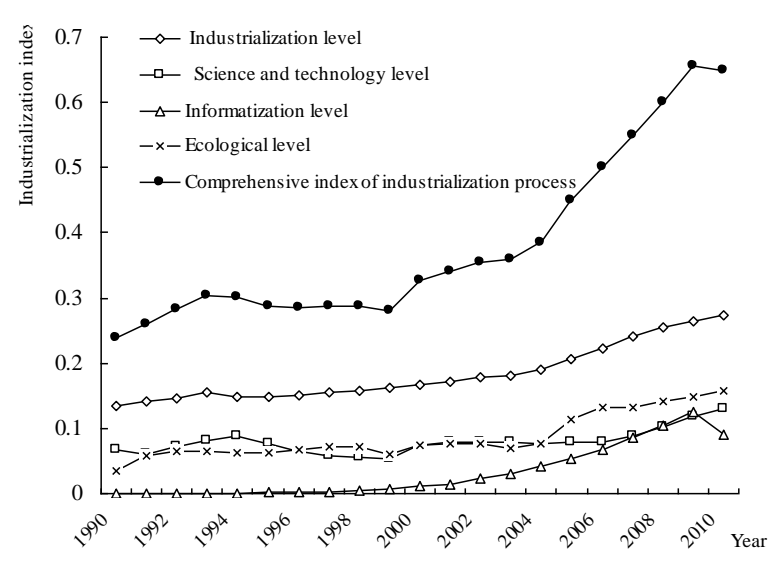

Fig.1. Changes of industrialization comprehensive evaluation value of Inner Mongolia during 1990 to 2010

the accelerated development stage in industrialization process.

D. The development level is unbalanced of each component index of industrialization.

Figure 1 showed that there are differences in each component index of industrialization in Inner Mongolia, and the change trend of each component index of industrialization is not same. The industrialization level index is the highest and the information level index is the lowest. Each component index has the increasing trend. During the study period, the industrialization level index increased 1.02 times, science and technology level index increased 0.92 times, information level index increased 303.34 times and ecological level index increased 3.49 times. It showed that the development speed of information level index is the fastest, while the development speed of science and technology level index is the slowest.

\section{CONCLUSION}

Base on the industrialization theory and the industrialization practice of Inner Mongolia, this paper establishes a comprehensive evaluation index system and standard, using AHP, PCA and WSM method to assess and analyze the industrialization process and evolution characteristics of Inner Mongolia during 1990 to 2010. Research shows that: the industrialization level of Inner Mongolia has continuously improved during the study period, it has entered the accelerated development of industrialization period since 2000 and it entered the middle stage of industrialization at present. There are certain differences between each component index of industrialization, the industrialization level index is higher and the informatization level index is lower. The development speed of informationization index is the fastest, and the development speed of science and technology index is the slowest.

\section{ACKNOWLEDGMENT}

This project is supported by the Project of National Natural Science Fund (No. 41261109) and Inner Mongolia Natural Science Fund Project (No.2012MS0617). 


\section{REFERENCES}

[1] Li Xinying. The study of environmental problems in process of Xinjiang industrialization. Doctoral dissertation of Xinjiang University, 2005.

[2] Wu Yiqing, Chen Yongguo. Measurement and comparative analysis of China's 31 provinces of new-type industrialization level. China Mechanical Engineering Society annual meeting proceedings, 2005, pp. 1435-1439.

[3] Li Xingjiang, Meng Qiumin. Comprehensive regional industrialization index system and evaluation. 1rd ed., vol. 42.Journal of Northwest Normal University, 2006, pp. 74-85.

[4] Chen Jiagui, Zhong Hongwu. The characteristics of comprehensive evaluation of the western region industrialization and stage. 1 rd ed., vol. 128. Development research, 2007, pp. 6-10.

[5] Li Tongning. Analysis on the new-type industrialization process monitoring of China and its provinces. 2rd ed., vol. 20 The soft science, 2006, pp.40-47.

[6] A.K.Bagchi. the new Palgrave Dictionary of Economics (in translation, second Vols.). Beijing: Economic Science Press, 1992.

[7] Zhang Peigang. The theory of development economics: agricultural industrialization problem of Changsha: Hunan publishing house, 1991.

*Correspondence to: Dr. Zhen Jiang-hong, professor of College of

Geography Science, Inner Mongolia Normal University. No. 81,

ZhaoWuDa Road, Hohhot 010022, China. Tel: 13074753291; Email:

zhenjianghong@sina.com 